\title{
Power Producer Production Valuation
}

M. Kněžek

The ongoing developments in the electricity market, in particular the establishment of the Prague Energy Exchange (PXE) and the associated transfer from campaign-driven sale to continuous trading, represent a significant change for power companies. Power producing companies can now optimize the sale of their production capacities with the objective of maximizing profit from wholesale electricity and supporting services. The Trading Departments measure the success rate of trading activities by the gross margin (GM), calculated by subtracting the realized sales prices from the realized purchase prices and the production cost, and indicate the profit \& loss (P\&L) to be subsequently calculated by the Control Department. The risk management process is set up on the basis of a business strategy defining the volumes of electricity that have to be sold one year and one month before the commencement of delivery. At the same time, this process defines the volume of electricity to remain available for spot trading (trading limits).

Keywords: Closed position, difference from plan fulfillment, forward price curve, future position, gross margin, historical position, internal regulation, mark to market, open position, power producer, planned production, profit \& loss, risk exposure, risk management committee, trading limits.

\section{Introduction}

To assess the performance of trading in electricity, it is advisable to measure the profitability of electricity trading position will be measured.

The profitability of an electricity trading position expresses the realized profit in relation to the expression of the closed position values and the expected profit with respect to the market value of the open position. It consists of the following two basic components:

- Closed position profitability ("realized profit") and

- Market value of the open position ("unrealized profit").

\section{Definition of a trading position}

Closed position profitability is calculated using the GM indicator equal to the difference between the sales revenues and the costs of acquisition and generation.

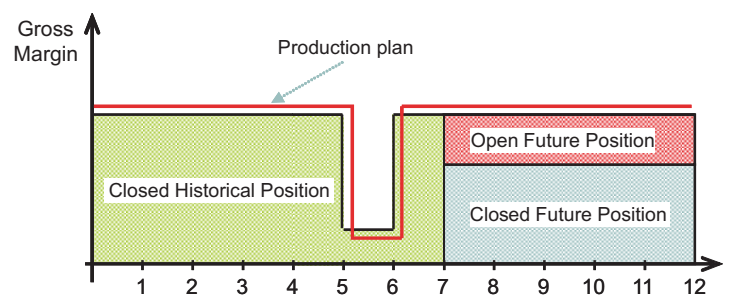

Fig. 1: An overview of the trading positions of a power producer

Open position profitability indicates what "profit might be expected from an open position, if it were closed today". In other words, it is the current market valuation of contracts constituting the open position using the Mark to Market method. GM is to be used for the open position valuation and for the purposes of determining its profitability.

A closed position consists of the closed historical position for the period from the beginning of the current year to the present date and the closed future position for the period from the next day within the selected future time window. The total value of GM from the closed position is calculated by adding up the closed historical positions and the closed future positions for a time window of one year.

\section{Closed historical position}

A closed historical position is a position for the period from the beginning of the current year to the present date, and is calculated as the sum of the concluded contract volumes per hour and day of the relevant period, while the following applies:

$$
\sum_{t d} q S_{t d}=\sum_{t d} q G_{t d}+\sum_{t d} q P_{t d}
$$

where $q S_{t d}$ is the volume of sold electricity for hour $t$ of day $d$ [MWh], $q G_{t d}$ is the generated volume of electricity for hour $t$ of day $d[\mathrm{MWh}]$ and $q P_{t d}$ is the volume of electricity purchased for hour $t$ of day $d$ [MWh].

The gross margin is used for determining the profitability of a closed historical position. GM from the closed historical position is to be calculated as the difference between the sales revenues (multiplied by the sold volume) and the production costs (the weighted value of the production prices multiplied by the produced volume) and the purchase costs (the weighted value of the purchase price multiplied by the purchase volume).

$$
\begin{aligned}
& G M_{-} C H P=\sum_{t d} G M_{-} C H P_{t d} \\
& =\sum_{t d} q S_{t d} \cdot \Phi p S_{t d}-\sum_{t d} q G_{t d} \cdot \Phi p G_{t d}-\sum_{t d} q P_{t d} \cdot \Phi p P_{t d},
\end{aligned}
$$

where $\Phi p S_{t d}$ is the weighted value of the sales prices [Kč], $\Phi p G_{t d}$ is the weighted value of the production prices [Kč ], and $\Phi p P_{t d}$ is the weighted value of the purchased prices [Kč].

\section{Closed future position}

A closed future position is a position for the period from the next day within the selected future time window, and is calculated as the sum of concluded contract volumes per hour 
and day of the relevant time window, while the following applies:

$$
\sum_{t d} q S_{t d}=\sum_{t d} q P G_{t d}+\sum_{t d} q P_{t d}
$$

where $q S_{t d}$ is the volume of sold electricity for hour $t$ of day $d$ [MWh], $q P G_{t d}$ is the planned electricity generation for hour $t$ of day $d$ [MWh], $q P_{t d}$ is the volume of electricity purchased for hour $t$ of day $d$ [MWh].

The gross margin is used for determining the profitability of a closed future position. GM from the closed future position is to be calculated as the difference between the sales revenues (multiplied by the sold volume) and the planned production costs (the planned value of the production prices multiplied by the produced volume) and the purchase costs (the weighted value of the purchase price multiplied by the purchase volume).

$G M_{-} C F P=\sum_{t d} G M_{-} C F P_{t d}$

$=\sum_{t d} q S_{t d} \cdot \Phi p S_{t d}-\sum_{t d} q P G_{t d} \cdot p P G_{t d}-\sum_{t d} q P_{t d} \cdot \Phi p P_{t d}$,

where $\Phi p S_{t d}$ is the weighted value of the sales prices [Kč], $p P G_{t d}$ is the planned value of the production prices $[\mathrm{Kc}]$ and $\Phi p P_{t d}$ is the weighted value of the purchase prices [Kč]

\section{Open future position}

An open future position is a position for the period from the next day within the selected future time window and is calculated as the difference between the planned volume of sold electricity, the planned volume of generated electricity and the planned volume of purchased electricity per hour and day of the relevant time window, while the following applies:

$$
\sum_{t d} q P S_{t d}=\sum_{t d} q P G_{t d}+\sum_{t d} q P P_{t d}
$$

where $q P S_{t d}$ is the planned volume of sold electricity for hour $t$ of day $d[\mathrm{MWh}], q P G_{t d}$ is the planned volume of generated electricity for hour $t$ of day $d[\mathrm{MWh}]$ and $q P P_{t d}$ is the planned volume of electricity purchased for hour $t$ of day $d$ [MWh].

The gross margin is used for determining the profitability of an open future position. GM from the open position is to be calculated as the difference between the planned sales revenues (the planned sales volume multiplied by the planned sales price - forward price curve) and the planned production costs (the planned generation volume multiplied by the planned production cost) and the purchase costs (the planned purchased volume multiplied by the relevant planned purchase price).

$G M_{-} O F P_{t d}=\sum_{t d} G M_{-} O F P_{t d}$
$=\sum_{t d} q P S_{t d} \cdot p P S_{t d}-\sum_{t d} q P G_{t d} \cdot p P G_{t d}-\sum_{t d} q P P_{t d} \cdot p P P_{t d}$,

where $p P S_{t d}$ is the planned value of the sales prices [Kč], $p P G_{t d}$ is the planned value of the production prices [Kč $]$ and $p P P_{t d}$ is the planned value of the purchased prices [Kč]

For the purposes of an open position Mark-to-Market valuation, the open position per hour has to be observed in order to be valued by the hourly forward price curve, which differentiates the PEAK and OFF-PEAK prices for sales and purchase.

\section{Total Gross Margin and difference from plan fulfillment}

The total GM value is calculated as the sum of the gross margins of the closed historical and future position and open future position, as follows:

$$
G M=G M M_{-} C H P+G M_{-} C F P+G M M_{-} O F P .
$$

The total difference from plan fulfillment will be given as the sum of the actual historical variance and the expected future variance in a one-year time window:

$$
\Delta=\sum_{t d} \Delta A c t_{t d}+\sum_{t d} \Delta F u t_{t d}
$$

The actual difference from plan fulfillment represents the profit/loss realized from plan fulfillment for the period from the beginning of the current year to the present date. It is to be calculated as the difference between the planned value of the GM of the closed historical position and the actual value of the GM of the closed historical position to the present date:

$$
\Delta A c t_{t d}=G M_{-} C H P p l-G M_{-} \text {CHPact. }
$$

The expected difference from plan fulfillment represents the projected unrealized profit/loss from plan fulfillment for the period from the next day within the selected future time window. It will be calculated as the difference between the planned value of the GM of the future position and the sum of the actual value of the GM of the closed future position and the GM of the open future position to the present date:

$\Delta F u t_{t d}=G M_{-} F P p l-G M_{-}$CFPact $-G M_{-}$OFPact.

\section{Risk exposure of open position}

Power producers, unlike pure electricity traders (involved in pure electricity purchase/sale and managing their position based on trading only), provide their sold electricity primarily by controlled generation, with purchases being of a complementary nature only. To avoid the risk exposure of an open position, their internal regulation states that:

- producers are only allowed to purchase electricity for a price that is lower than the cost price by a certain coefficient

- producers are allowed to sell electricity for a price that is higher than the cost price by a certain coefficient

- producers are allowed to sell electricity up to the volume that they are able to generate.

For the above reasons, power producers are usually not exposed to risks implied by the fluctuating market price of electricity from an open position and, therefore, the calculation of Value at Risk has no rationale.

\section{Conclusion}

Power producers are exposed to energy market risk through trading in power and power related products as well as all components associated with electricity production. The purpose of this paper is to manage power producers' trading activities and their exposure to energy market risk, in particular the risks associated with the volatile and unpredictable 
markets in electricity, ancillary services and $\mathrm{CO}_{2}$ and the associated transactions of over-the-counter and exchange-traded derivative contracts, both to hedge their position and to optimize their position.

\section{Acknowledgments}

The research described in this paper was supervised by Prof. Ing. O. Starý, CSc., FEE CTU in Prague and also by Doc. Ing. Jaroslav Knápek, CSc., FEE CTU in Prague.

\section{References}

[1] Kněžek, M.: Managing Electricity Market Risk. Modern Trends of Industrial Enterprises Management Conference, Department of Economics, Management and Humanities, Czech Technical University in Prague.

[2] Kněžek, M.: Electricity Market Risk Management. Poster 2007, Dept. of Economics, Management and Humanities, Czech Technical University in Prague.

[3] Kněžek, M.: Risk Management in the Electricity Market. Diploma Thesis, 2007, Dept. of Economics, Management and Humanities, Czech Technical University in Prague.

[4] Kněžek, M.: Electricity Risk Management. Student's Scientific and Technical Project, 2006, Dept. of Economics, Management and Humanities, Czech Technical University in Prague.
[5] Kněžek, M.: Financial Derivatives in Power Engineering. Semester Project, 2006, Dept. of Economics, Management and Humanities, Czech Technical University in Prague.

[6] Briys, E., Mai, H., Bellalah, M., Varenne, F.: Options, Futures and Exotic Derivatives. Wiley 1998. ISBN 0417969095

[7] Holton, G. A.: Value at Risk. Elsevier Academic Press 2003. ISBN 0123540100.

[8] Leppard, S.: Energy Risk Management. Risk Books 2005. ISBN 1904339743.

[9] McClave, J. T., Benson, P. G., Sincich, T.: Statistics for Business and Economics ( $7^{\text {th }}$ Edition), Prentice Hall 1998. ISBN 0139505458.

[10] Wengler, J.: Managing energy risk. Pennwell Books 2001. ISBN 0878147942.

Ing. Marian Kněžek

e-mail: knezem1@fel.cvut.cz

Department of Economics, Management and Humanities

Czech Technical University

Faculty of Electrical Engineering

Technická 2

16627 Praha, Czech Republic 